\title{
Acquisition of Breadth and Depth of Vocabulary Knowledge by Secondary School Learners of English in the Multilingual Context: A Case of Dodoma, Tanzania
}

\author{
Godson Robert Mtallo \\ Orcid: https://orcid.org/0000-0001-6243-1744 \\ Department of Foreign Languages and Linguistics, University of Dar es Salaam, Tanzania \\ Email: godson.mtallo@cbe.ac.tz \\ Gerald Kimambo, PhD \\ Orcid: https://orcid.org/0000-0002-5859-5356 \\ Department of Foreign Languages and Linguistics, University of Dar es Salaam, Tanzania \\ Email: kimambog@udsm.ac.tz
}

Corresponding Mail: godson.mtallo@cbe.ac.tz

\begin{abstract}
Copyright resides with the author(s) in terms of the Creative Commons Attribution CC BY-NC 4.0. The users may copy, distribute, transmit and adapt the work, but must recognize the author(s) and the East African Journal of Education and Social Sciences
\end{abstract}

\begin{abstract}
This study examined the relationship between the breadth and depth of vocabulary knowledge among Tanzanian learners who use English as a foreign language. It employed a convergent parallel mixed-methods design which simultaneously collected qualitative and quantitative data from a sample of 320 secondary school learners from Dodoma City and Chamwino District and eight English language teachers with at least five years of teaching experience. The study employed two different language tests, namely the New Vocabulary Levels Test and the Word Association Test, to collect quantitative information on the breadth and depth of vocabulary knowledge, respectively. It used semi-structured interviews with the selected English language teachers to obtain qualitative data to supplement the quantitative data. A Pearson correlation coefficient indicated a positive relationship between breadth scores and depth scores; as breadth scores increased, depth scores also increased. The results imply that the breadth and depth of vocabulary knowledge are like two sides of the same coin, which cannot be separated. Thus, the higher the learners' performance in the breadth test, the higher their performances in the depth test. In this regard, it suffices to conclude that vocabulary use is part of vocabulary knowledge. The obtained results call for a comparative longitudinal study to trace the development of vocabulary knowledge among the compared groups over an extended period.
\end{abstract}

Keywords: Language acquisition; Breadth of vocabulary knowledge; Depth of vocabulary knowledge; Multilingualism

How to cite: Mtallo, G. R. and Kimambo, G. (2022). Acquisition of Breadth and Depth of Vocabulary Knowledge by Secondary School Learners of English in the Multilingual Context: A Case of Dodoma, Tanzania. East African Journal of Education and Social Sciences 3(1), 38-48. Doi: https://doi.org/10.46606/eajess2022v03i01.0144.

\section{Introduction}

Recently, second/foreign language vocabulary acquisition has been an increasingly interesting topic for researchers, teachers, curriculum designers, theorists and others involved in second/foreign language learning. This is based on the view that vocabulary is the most important aspect of language studying (Shen, 2008). Second/foreign language learners often cite the shortage of vocabulary as one of the limitations to text comprehension (Nation, 1990). Other scholars hold that vocabulary load is one of the main 
challenges facing learners in comprehending a particular text; thus, what troubles SL/FL readers is not lack of reading strategies but insufficient vocabulary in that particular language (Haynes \& Baker, 1993).

Elmasry (2012) asserts that at school, students need to learn many new words to increase their vocabulary size (breadth). At the same time, they need to know other new meanings and meaning relations relevant to these new words, which eventually enriches the students' use of the known words (depth). Therefore, SL/FL learners extend their vocabulary knowledge in two ways: breadth and depth.

Elmasry further argues that Learners do not only need to know the words with their superficial meanings (breadth), but they also need to know the words with their synonyms, derivations and collocations (depth). For instance, learners may know the primary meaning of the word 'active' (breadth), but they might not know its various synonyms like 'lively, hard-working and operating'; its derivations like activation, activity and activist' as well as its collocations like 'active participation and active support' (depth). In this regard, learners are required to know the meaning of the word and its associates to assist them in comprehending written texts without any hurdles (Elmasry, 2012).

In second language learning, it has been controversial in deciding whether vocabulary use is part of vocabulary knowledge. There has been a hot debate among researchers who have attempted to explore whether the superficial use of a particular vocabulary item entails its in-depth understanding, given the argument that learners do not only need to know the words with their superficial meanings (breadth), but they also need to know the words with their synonyms, derivations and collocations (depth) (Elmasry, 2012). In this regard, while some scholars (Kelly, 1985; Meara, 1996a; Nation, 2001; Schmitt, 2005; Vermeer, 2001) argue that vocabulary use is part of vocabulary knowledge, others(Bialystok, 2017; Gass, 2008; Gass and Selinker, 2001; Henriksen, 1999) argue that the two should be considered as different dimensions.

Besides, Gass (12008) noted that it is useful to realise the differences between knowledge and control of vocabulary. Similarly, Henriksen (1999, p.314) argued, "the fact that learners cannot use a word correctly or access it freely in production does not mean they do not know the word; they have not achieved adequate control over word access."

Vermeer (2001) argues that there is no theoretical difference between the breadth and depth of word knowledge. The two are strongly related to each other; the greater one's vocabulary, the deeper one's vocabulary knowledge, and vice versa. He further claims, "deeper knowledge of words is the result of knowing more words or that, conversely, the more words someone knows, the finer the networks and the deeper the word knowledge." In this regard, Vermeer (2001) argues that the breadth and depth of vocabulary should be regarded as two dimensions of the same phenomenon.

Although, in theory, the separation of vocabulary knowledge and use sounds reasonable, there is no sufficient empirical work to investigate its practicability. Such a contradiction needs further investigation to clarify whether vocabulary use is part of vocabulary knowledge. Therefore, this study filled this lacuna by examining the relationship between the scores on the breadth and depth of English vocabulary by Tanzanian secondary school learners in the multilingual Tanzanian context, where English is acquired as a foreign language.

\section{Related Literature}

Several researchers have made seminal contributions to the relationship between the breadth and depth of vocabulary knowledge. Shen (2008), for instance, reviewed various studies to establish the relationship between the breadth and depth of vocabulary knowledge and EFL reading comprehension in different contexts. Having gone through various empirical studies, Shen realised a positive correlation between the depth of vocabulary knowledge, breadth of vocabulary knowledge and reading comprehension. Moreover, the depth of vocabulary knowledge was found to predict the scores on reading comprehension more than the breadth of vocabulary knowledge. Relying on the literature reviewed by Shen might not be possible to generalise the results as they mainly addressed the acquisition based on European and Asian contexts. This study found the need to address the acquisition based on the African context, specifically on the learners' social and cultural settings, to see whether different results may be found when the study is situated in different social contexts.

Similarly, Bardakci (2016) used two different vocabulary tests to analyse the effects of breadth 
and depth of vocabulary on SL vocabulary profiles. Then, the obtained scores were compared to their profile scores. Findings revealed that both the breadth and depth of vocabulary knowledge had significant effects on the SL vocabulary profiles of the EFL learners; however, the depth of vocabulary knowledge appeared to be a better predictor of vocabulary profiles than the breadth of vocabulary knowledge. The study employed a quantitative approach to address this particular problem. Nevertheless, a single approach alone could not offer an accurate picture of the acquisition. Therefore, the study would fall short of generalisation. Consequently, this study employed a mixed-methods approach, integrating qualitative and quantitative approaches.

A more comprehensive description can be found in Vermeer (2001). The scholar conducted two empirical studies. The first one employed fifty (50) Dutch monolingual and bilingual students to explore how the breadth and depth of word knowledge are related. The second study used 1,600 Dutch monolinguals and bilinguals aged between 4 and 7 years to examine the relationship between the opportunity of understanding a phrase and its input frequency. The two studies realised that there has been no conceptual distinction between breadth and depth of vocabulary and that the acquisition of both dimensions of vocabulary understanding had suffered from similar elements of some of the monolingual and bilingual speakers. The results, in addition, suggested that correlations between the audio system' breadth and depth of vocabulary expertise were very high. This was also consistent with the chance of knowing a word that is regarded to be strongly associated with its frequency of use. However, the study put the monolingual and bilingual Dutch speakers in the same category, as if they shared their backgrounds. Thus, one can reasonably question the validity of the obtained results. Thus, a study that would consider learners' language backgrounds in addressing the acquisition of the breadth and depth of vocabulary knowledge was worth conducting.

Studies on vocabulary knowledge are well documented since one of the significant predictors of the breadth and depth of vocabulary knowledge is the strategies that focus on learning the forms and associative meaning of words. This is well evidenced by Zhang and Lu (2015) who researched the relationship between vocabulary learning strategies and the breadth and depth of vocabulary knowledge. Data for this study were collected through the Vocabulary Levels Test, a Meaning Recall Task and the Depth of Vocabulary Knowledge Test administered to 150 first-year university students in China. The study employed structural equation modelling to assess how learning strategies predict the breadth and depth of vocabulary. The study further concluded that recognising or recalling the meaning of vocabulary items is also affected by the learning strategies of the same type.

The steps taken by Zhang and Lu (2015) are similar to Mehrpour, Razmjoo and Kian (2011) who investigated the roles of vocabulary knowledge in the reading comprehension performance of EFL learners in Iran. The study achieved its objectives by administering two tests to 60 participants. The first test measured the breadth and depth of vocabulary knowledge, and the second test measured reading comprehension. Findings indicated that the depth of vocabulary knowledge makes a more important contribution to reading comprehension among EFL learners than the breadth of vocabulary knowledge, although both vocabulary dimensions work together. A very positive correlation between the breadth and depth of vocabulary knowledge is realised in this study. The larger the vocabulary size, the deeper the knowledge of the vocabulary items.

Although the breadth and depth of vocabulary knowledge have been studied from different perspectives, the related literature lacks serious studies on the relationship between these dimensions of vocabulary knowledge based on the learners' language backgrounds. This paper has attempted to fill this lacuna by examining the relationship between the breadth and depth of English vocabulary knowledge among multilingual Tanzanian secondary school learners from different language backgrounds. In this regard, studying the link between the breadth and depth of English vocabulary by considering learners differences in language backgrounds will not only offer more evidence on how the two vocabulary dimensions relate but also helps to have a unified kind of analysis which will eventually contribute to the existing debates, particularly in addressing whether using a particular vocabulary item implies its complete understanding. Again, since the reviewed studies concentrated mainly on European and Asian contexts, the link between the breadth and depth of English vocabulary in African multilingual contexts is scarcely explored. A study in a multilingual context 
provides a clear picture of vocabulary acquisition based on learners' language backgrounds since no traceable research has been reported addressing the same in Tanzania.

\section{Methodology of the Study \\ Research Design}

This study employed a mixed-methods approach whereby both qualitative and quantitative data were collected and analysed concurrently. This is based on Tashakkori and Teddlie's (2003) view that the use of both quantitative data and qualitative data in a single study helps in supplementing each other; thus, it becomes easy to have a complete picture of the research problem than when relying on one type of data (Tashakkori \& Teddlie, 2003). In this mixed-methods study, the quantitative strand is the dominant one.

The study adopted a convergent parallel mixedmethods design to give room for the two datasets (quantitative and qualitative) to interact, aiming at providing a more profound understanding of the phenomenon using both strands. The decision to use a convergent parallel mixed-methods design is built on Creswell (2014) that the design is relevant when the focus is on getting a more profound understanding of the phenomenon through both quantitative and qualitative strands, especially when the data are collected using parallel variables, constructs, or concepts.

\section{Study Area}

This study was conducted at selected secondary schools in Dodoma, specifically Dodoma City and Chamwino District to take aboard the rural-urban aspects in studying vocabulary acquisition. It was expected that in Dodoma, there would be a high possibility of getting learners from different parts of the country with different language backgrounds. This is because the region is located in the central part of Tanzania and has been experiencing a rapid population growth rate of 23 per cent over the past ten years (URT, 2016, p.69). A sharp increase in population in the region is partly linked to the government's move from Dar es Salaam to Dodoma and the establishment of several higher learning institutions. This increase in population in Dodoma ensured secondary school learners with different language backgrounds.

\section{Population and Sampling}

The population of this study comprised 51,192 secondary school learners from 83 secondary schools in Dodoma City and Chamwino District in the Dodoma Region (BEST, 2021). The study focused only on those learners who are Tanzanians by birth to get a clear picture of the acquisition in the Tanzanian social context. Learners were identified by filling out the Language Background Questionnaires which comprised the particular identification features. It involved eight secondary schools from the two territories (four privatelyowned secondary schools and four governmentowned secondary schools) whereby 320 learners were employed; forty (40) learners from each school in a proportion of twenty (20) learners from each form class (Form III-IV) for administering quantitative instruments and 8 English language teachers from these schools who had been actively involved in teaching English as an academic subject were selected for interviews. In total, 328 respondents participated in the study. The study involved only Form Three and Form Four learners since these form level classes were expected to have sufficiently been oriented to English vocabulary. Therefore, it would be easy to measure the breadth and depth of their English vocabulary knowledge. The justification for using the particular sample size is built on Mason (2002, p.13) that, in mixed methods, the decision to use a specific sample size should consider both qualitative and quantitative strands. Whereas in the qualitative strand the sample size should typically be small (at most 30 cases), in the quantitative strand, the sample should be large enough to establish representativeness (usually 300-500 units).

Since the population was 51,192 learners from the two territories, the mentioned sample size was arrived at through the formula for large samples as modified from Poate and Daplyn (1993):

$n=\frac{\mathrm{Z}^{2} \mathrm{C}^{2}}{\mathrm{X}^{2}}$

Whereby,

$n$ stands for the minimum sample size, $\mathrm{Z}$ for the selected critical value of desired confidence level, which is 1.96 for a $95 \%$ confidence level, $C$ is the proportion in the largest population which is $50 \%, X$ is the degree of accuracy or acceptable margin of error, set at 5 per cent.

Therefore, $n=\frac{(1.96)^{2}(50)^{2}}{(5)^{2}}=384.16 \approx 384$

$(5)^{2}$

However, based on the rule of thumb as Saunders (2012) presented, a minimum sample size of 30 is 
acceptable for statistical analysis. Accordingly, the proposed sample of 328 was considered adequate and appropriate for the study. In this mixedmethods study, since the quantitative strand is dominant, the sample of qualitative participants was included in the larger quantitative sample as suggested by Creswell (2014). Besides, a sample for schools was based on Creswell (2014) that researchers should aim for a small sample size of around 10 if no new characteristic is realized in a population.

As far as the mixed methods approach is concerned, the selection of cases for the proposed study was made using both probability sampling (to increase external validity) and purposive sampling strategies (to increase transferability) (Onwuegbuzie \& Collins, 2007). This study purposively selected teachers using snowball sampling (cf. Creswell, 2014) to easily identify teachers with at least five years of teaching experience. In snowball sampling, participants are asked to assist researchers in identifying other potential subjects. The procedure considered those teachers who had been teaching English for at least five (5) years. The researchers hoped that the one with at least five years or more experience teaching English as an academic subject would provide useful information on English vocabulary acquisition. In this regard, it was important to rely on referrals from initially sampled respondents to other teachers believed to have the required teaching experience. Secondly, stratified random sampling helped to select secondary school learners from the secondary schools. The justification for using this technique is that it allowed the researcher to work with specific groups from different language backgrounds. To avoid bias, the study involved both private and public secondary schools using systematic random sampling. Hence, the selected secondary schools accurately represented the entire population. Besides, the decision to select both private and public secondary schools was built on the assumptions that learners from private secondary schools might differ in language backgrounds from those who are studying in public secondary schools; therefore, selecting learners based on one category only might not bring an accurate representation of the population.

\section{Data Collection Methods}

In this study, semi-structured interviews were used in collecting qualitative data while the New Vocabulary Levels Test (NVLT) (McLean \& Kramer,
2015), Word Association Test (WAT) (Read, 1993; Read, 1998), and Language Background Questionnaire (LBQ) were used to collect quantitative data. The qualitative data were collected after the quantitative ones since the qualitative data helped to explain the quantitative results. Also, employing the two instruments ensured triangulation which is important in qualitative studies.

\section{Data Collection Procedures}

The researchers administered LBQ to identify potential respondents (learners from different language backgrounds) selected for administering both NVLT and WAT. Respective teachers assisted the researchers in invigilating the tests. After that, they participated in semi-structured interviews. This is to say; the study collected data through LBQ, NVLT, WAT and semi-structured interviews. After the data collection process, the tests were marked using marking guides: Read (1998) for WAT and McLean and Kramer (2015) for NVLT. The obtained quantitative data were coded and entered into the Statistical Package for the Social Sciences (SPSS 25) for analysis. The obtained qualitative data were compiled in a special format for content analysis.

\section{Statistical Treatment of Data}

The quantitative data obtained through NVLT and WAT were analysed using correlation analysis in SPSS Version 25 to ascertain statistically significant results to address the research question. A correlation analysis was used to achieve the study objective where breadth scores and depth scores were calculated by the following formula.

the $r=\frac{\sum\left(x_{i}-\bar{x}\right)\left(y_{i}-\bar{y}\right)}{\sqrt{\sum\left(x_{i}-\bar{x}\right)^{2}\left(y_{i}-\bar{y}\right)^{2}}}$

Where $r$ is the correlation coefficient, $x_{i}$ are breadth scores, $y_{i}$ are depth scores, $\bar{x}$ is mean breadth score and $\bar{y}$ is depth mean score.

The quantitative data were supplemented by the qualitative data obtained through interviewing secondary school teachers who had been teaching the English language to the students for at least five (5) years. The recorded interviews were analysed through content analysis. After formulating the relevant themes, the researchers matched qualitative findings with the existing theory and the findings from other relevant empirical studies. The analysis involved eight key informants who had agreed to participate in the semi-structured interviews. The key informants were selected based 
on their experiences in teaching English to secondary school students.

\section{Findings and Discussions}

All questions from the LBQ were coded in SPSS software as variables. The Yes and No responses were coded as 0 for No and 1 for Yes. On the side of the home, playground and class languages, responses were coded as 1 for ECLs, 2 for Kiswahili and 3 for English. Lastly, breadth and depth scores were obtained from students tests and were entered directly in SPSS software as real values.

Table 1: A Summary of the language attributes of the Participants $(n=320)$

\begin{tabular}{|c|c|c|c|}
\hline & & Frequency(N) & Per cent (\%) \\
\hline \multicolumn{4}{|l|}{ First language } \\
\hline & ECLs & 43 & $13.4 \%$ \\
\hline & Kiswahili & 269 & $84.1 \%$ \\
\hline & English & 8 & $2.5 \%$ \\
\hline \multicolumn{4}{|l|}{ Fathers First language } \\
\hline & ECLs & 125 & $39.1 \%$ \\
\hline & Kiswahili & 177 & $55.3 \%$ \\
\hline & English & 18 & $5.6 \%$ \\
\hline \multicolumn{4}{|l|}{ Mothers First language } \\
\hline & ECLs & 136 & $42.5 \%$ \\
\hline & Kiswahili & 174 & $54.4 \%$ \\
\hline & English & 10 & $3.1 \%$ \\
\hline \multicolumn{4}{|l|}{ Caregivers First language } \\
\hline & ECLs & 91 & $28.4 \%$ \\
\hline & Kiswahili & 229 & $71.6 \%$ \\
\hline & English & 0 & $0.0 \%$ \\
\hline \multicolumn{4}{|l|}{ Language while growing } \\
\hline & ECLs & 24 & $7.5 \%$ \\
\hline & Kiswahili & 276 & $86.3 \%$ \\
\hline & English & 20 & $6.3 \%$ \\
\hline \multicolumn{4}{|l|}{ Language at home } \\
\hline & ECLs & 21 & $6.6 \%$ \\
\hline & Kiswahili & 274 & $85.6 \%$ \\
\hline & English & 25 & $7.8 \%$ \\
\hline \multicolumn{4}{|l|}{ Language in class } \\
\hline & ECLs & 0 & $0.0 \%$ \\
\hline & Kiswahili & 37 & $11.6 \%$ \\
\hline & English & 283 & $88.4 \%$ \\
\hline \multicolumn{4}{|l|}{ Language on the playground } \\
\hline & ECLs & 7 & $2.2 \%$ \\
\hline & Kiswahili & 294 & $91.9 \%$ \\
\hline & English & 19 & $5.9 \%$ \\
\hline \multicolumn{4}{|l|}{ Age } \\
\hline & Mean & \multicolumn{2}{|c|}{16.13} \\
\hline & Minimum & \multicolumn{2}{|c|}{14} \\
\hline & Maximum & \multicolumn{2}{|c|}{20} \\
\hline \multicolumn{4}{|l|}{ Speaking languages } \\
\hline & Mean & \multicolumn{2}{|c|}{2.57} \\
\hline & Minimum & \multicolumn{2}{|c|}{1} \\
\hline & Maximum & \multicolumn{2}{|c|}{6} \\
\hline
\end{tabular}

Semi-structured interviews involved eight (8) secondary school teachers who had been teaching the English language to Form III/IV students for at least five (5) years. The recorded interviews were analysed through content analysis. After formulating the relevant themes, the researchers matched qualitative findings with the existing theory and the results from other relevant empirical studies. 
Semi-structured interviews involved eight (8) secondary school teachers who had been teaching the English language to Form III/IV students for at least five (5) years. The recorded interviews were analysed through content analysis. After formulating the relevant themes, the researchers matched qualitative findings with the existing theory and the results from other relevant empirical studies.

Research Question: What is the relationship between the scores on the breadth and depth of English vocabulary among secondary school Tanzanian learners?

The relationship between the breadth and depth test scores was analysed using correlation analysis. Results in Table 3 show that the Pearson correlation coefficient is 0.433 and is statistically significant $(p<0.05)$. According to Ratner (2009) the Pearson correlation coefficient of 0.433 indicates a moderate positive relationship between breadth and depth scores. A demarcation for a weak, moderate and strong correlation was decided based on Ratner (2009) who established that values between 0 and 0.3 ( 0 and 0.3 ) indicate a weak positive (negative) linear relationship through a shaky linear rule; values between 0.3 and 0.7 (0.3 and 0.7$)$ indicate a moderate positive (negative) linear relationship through a fuzzy-firm linear rule and values between 0.7 and 1.0 ( 0.7 and 1.0 ) indicate a strong positive (negative) linear relationship through a firm linear rule.

Table 2: Interview Participants' attributes

\begin{tabular}{llllll}
\hline Cases & Age Group & Sex & Experience(Years) & Teach English & Class \\
\hline Case1 & $30-39$ & Female & 3 to 6 & Yes & III \& IV \\
Case2 & $30-39$ & Female & 7 to 10 & Yes & III \& IV \\
Case3 & $30-39$ & Male & 3 to 6 & Yes & III \& IV \\
Case4 & $40-49$ & Male & 15 to 18 & Yes & III \& IV \\
Case5 & $30-39$ & Female & 7 to 10 & Yes & III \\
Case6 & $30-39$ & Female & 3 to 6 & Yes & III \& IV \\
Case7 & $20-29$ & Female & 3 to 6 & Yes & III \\
Case8 & $30-39$ & Male & 11 to 14 & Yes & III \& IV
\end{tabular}

Table 3: Correlations between Breadth scores and Depth scores

\section{Statistic}

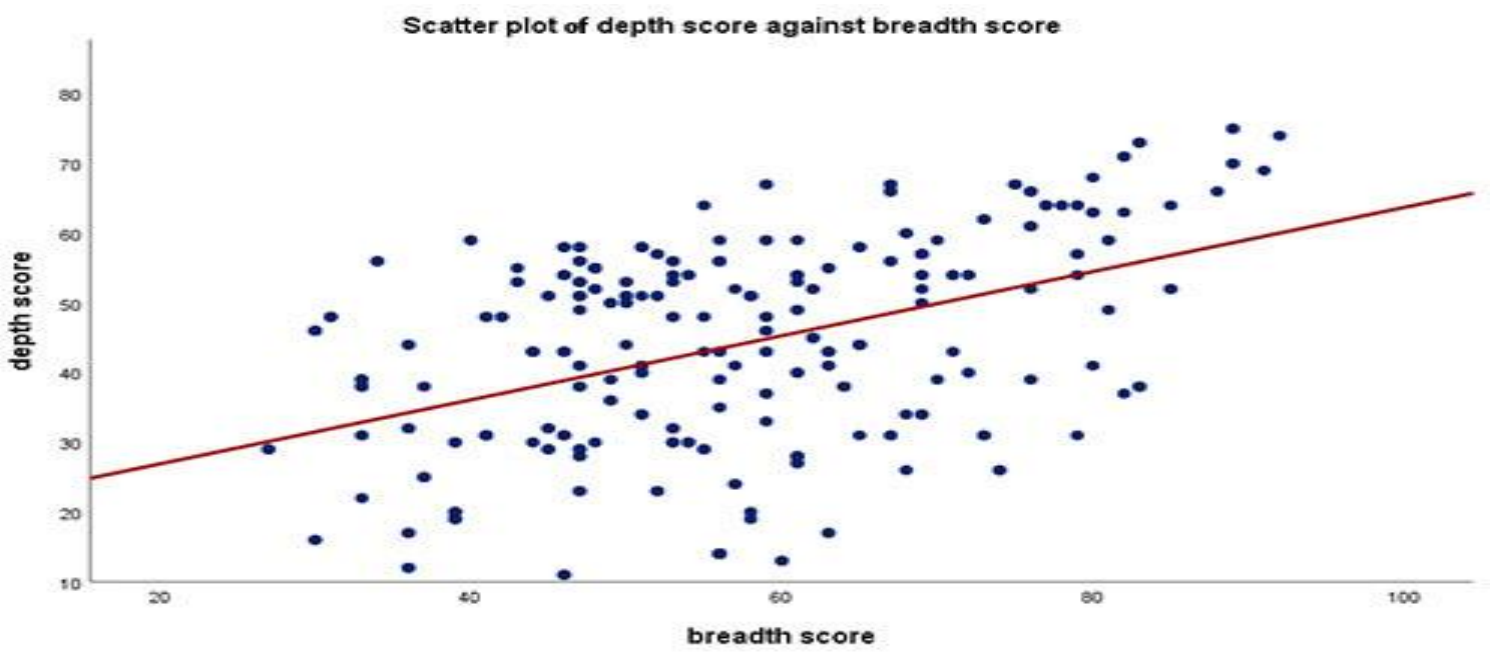

Figure 1: Scatter Plot of the Relationship between Breadth Scores and Depth Scores

The scatter plot (Figure 1) supports the results of indicates a positive relationship between breadth the Pearson correlation coefficient where it scores and depth scores. As the breadth score 
increases, the depth score also increases, indicating a positive relationship. Besides, some points are far from a straight line, making it a moderate relationship.

The results strongly imply that the breadth and depth of vocabulary knowledge are like two sides of the same coin; they cannot be separated. In other words, the results support the argument that vocabulary use is part of vocabulary knowledge (Nation, 2001; Vermeer, 2001), as the higher the learners' performance in the breadth test, the higher their performance in the depth test.

The obtained quantitative information receives strong support from the qualitative side. Most of the interviewed participants shared a similar experience regarding how their learners acquire the breadth and depth of English vocabulary knowledge. The study participants shared the following experience:

$$
\begin{aligned}
& \text { For me, there is no way I can } \\
& \text { separate the use of a particular } \\
& \text { vocabulary item from one's } \\
& \text { understanding. If a learner knows } \\
& \text { the meaning of a certain English } \\
& \text { word, he can also grasp its meaning; } \\
& \text { thus, it becomes easy to use the } \\
& \text { same word in different contexts } \\
& \text { (Case 2). }
\end{aligned}
$$

In line with the previous participant's experience, another participant added:

In my teaching experience, I have noted that those learners who are either motivated or are from supportive English-speaking backgrounds acquire so many English words. Sometimes, I'm surprised to hear them using some English words beyond my understanding, as they frequently use English dictionaries. What amazes me is seeing how they can use those words in different contexts in a sentence (Case 6).

The argument raised by the sampled participants concurs with the findings from the quantitative analysis, pointing out that there is a strong relationship between having a certain size of English vocabulary items and understanding them. This means learners who are said to have a good size of English vocabulary items in their linguistic repertoire will also imply their wider understanding of the same vocabulary items.

The study findings contribute to the ongoing debate on language learning, especially in confirming whether vocabulary use is part of vocabulary knowledge. The results agree with other scholars such as Kelly (1985), Meara (1996), Nation (2001), Schmitt (2005), and Vermeer (2001), who argued that vocabulary use is part of vocabulary knowledge such that the superficial use of a particular vocabulary item entails its in-depth understanding. The data show that learners simultaneously acquire words in their superficial meanings (breadth) as well as their synonyms, derivations, and collocations (depth).

Similarly, the results correspond to Vermeer's (2001) argument that there is no conceptual distinction between the breadth and depth of word knowledge and that the two are strongly related to each other. Vermeer further asserts, "deeper knowledge of words is the consequence of knowing more words or that, conversely, the more words someone knows, the finer the networks and the deeper the word knowledge." In this regard, Vermeer (2001) asserts that the breadth and depth of vocabulary should be regarded as two dimensions of the same phenomenon.

Similar results were found by Bardakci (2016) who studied the breadth and depth of vocabulary knowledge and their effects on SL vocabulary profiles. In this study, Bardacki measured the breadth and depth of vocabulary knowledge using two different vocabulary tests, and the scores they obtained were hierarchically regressed on their profile scores. Results suggested that both breadth and depth of vocabulary knowledge are important determinants of the learners' vocabulary profile.

Besides, Li and Kirby (2015) contributed to the debates by exploring the relationship between two dimensions of vocabulary knowledge, namely breadth of vocabulary knowledge (the number of words known) and depth of vocabulary (the richness of word knowledge), among high school students in China who learn English as a second language. Their results agree with the current study results; they revealed that the breadth and depth of vocabulary were moderately correlated.

Likewise, in examining the relationship between breadth and depth of vocabulary knowledge and reading comprehension in the English as a foreign language (EFL) context in UAE, Elmasry (2012) 
realised a moderate positive intercorrelation among the scores in the three language tests. The results implied a positive association between students' vocabulary depth and lexical inferencing ability. Accordingly, Elmasry confirmed the importance and value of developing students' breadth and depth of vocabulary knowledge in EFL classrooms simultaneously.

When asked to give their opinions on the contribution of multilingualism in the acquisition of vocabulary knowledge, most of the interviewed participants opined that multilingualism determines the rate of acquiring vocabulary breadth and depth such that, in a situation where learners are exposed to more than two languages, they find themselves in a hard time acquiring either of the languages. Consequently, learners end up acquiring each language partially. For instance, in Tanzania, multilingual learners are obliged to acquire English as a foreign language when the acquisition of Kiswahili as a second language is still in its infancy. Consequently, they find themselves incompetent in all languages. This is to say that Tanzanian learners start learning English as a foreign language while developing their first (or home) language. Hence, they acquire only a few vocabulary items, which consequently hinders their communication through the medium of English.

The scenario above received strong support from some interviewed participants. Case 1, for instance, had the following to say:

Truly, the transition from Kiswahili to English among these students takes place abruptly since students are forced to speak English throughout the school premises when they join secondary school level while they have not yet developed enough competency in Kiswahili. In this case, it becomes difficult for their teachers to teach them the new language.

Another participant added:

Most of my students acquire English as a third language, with ECLs and Kiswahili being acquired as a first and second language, respectively, though there are cases where some students acquire Kiswahili as a first language. Those students whose language background begins with an ECL face a challenge in acquiring English vocabulary; thus, they end up acquiring few English vocabulary items (Case7).

Based on the opinions of the interviewed participants, it is noted that, even though Tanzanian learners acquire the breadth and depth of English vocabulary simultaneously, they still face some challenges in acquisition because of being exposed to a multilingual environment where more than two languages are used interchangeably. In this case, learners experience linguistic consequences caused by mixed languages within a linguistic milieu.

\section{Empirical Implications of the Study}

Understanding the relationship between the breadth and depth of English vocabulary is of prime importance in second/foreign language acquisition. Some scholars have researched the relationship between these two domains of vocabulary knowledge (Bardakci, 2016; Elmasry, 2012; Li \& Kirby, 2015). Nevertheless, this study's findings add more knowledge to the field of second language acquisition, particularly on the relationship between the breadth and depth of English vocabulary knowledge focusing on the learners' language backgrounds. The study has provided a unified analysis that eventually contributes to the current debate on whether vocabulary use is a part of vocabulary knowledge. The study has confirmed that using a particular vocabulary item entails an indepth understanding.

\section{Conclusions and Recommendations Conclusions}

The study realized a positive relationship between the breadth scores and depth scores such that an increase in breadth scores was found to be in line with the increase in depth scores. This confirms that vocabulary use is part of vocabulary knowledge. Thus, learners simultaneously acquire words in their superficial meanings (breadth) and their synonyms, derivations, and collocations (depth). The acquisition of the breadth and depth of vocabulary knowledge co-occurs since both dimensions depend on each other. In this regard, it is reasonable to conclude that vocabulary use is part of vocabulary knowledge.

\section{Recommendations}

To better understand how different language backgrounds influence their vocabulary growth, one should conduct a longitudinal study to trace vocabulary development among the compared 
groups over time. This would help examine how language backgrounds influence individual differences in vocabulary developmental profiles. This could not employ a longitudinal approach due to limited time and other resources. This calls for future studies to work on this aspect on a longitudinal basis.

Moreover, a comparative longitudinal study to trace the development of vocabulary knowledge among the compared groups over an extended period is worth conducting. Such a study will offer a better understanding of how different language backgrounds influence individual differences in vocabulary developmental profiles. For instance, one may consider tracing the growth of vocabulary knowledge among the compared language groups from a certain education level to another.

\section{References}

Bardakci, M. (2016). Breadth and depth of vocabulary knowledge and their effects on SL vocabulary profiles. English Language Teaching, 9 (4).

BEST. (2021). Basic Education Data 2021. www.tamisemi.go.tz.

Bialystok, E. (2017). Second language acquisition and bilingualism at an early age and the Impact on Early Cognitive Development. York University: Second Language Encyclopedia on Early Childhood Education.

Creswell, J. W. (2014). Research design. Thousand Oaks, California: Sage Publications, Inc.

Elmasry, H. I. (2012). Depth and breadth of vocabulary knowledge. Mansoura University: Master of Education Dissertation.

Gass, S. (2008). Second language vocabulary acquisition. Annual review of applied linguistics, 9, 92-106.

Gass, S., \& Selinker, L. (2001). Second language acquisition. Mahwah, New Jersey, London: Lawrence Erlbaum Associates.

Haynes, M., \& Baker, T. (1993). American and Chinese readers learning from lexical familiarization in English Texts. In T. Huckin, M. Haynes, \& J. Coady, Second Language Reading and Vocabulary Acquisition (pp. 130-152). Norwood, NJ: Ablex.
Henriksen, B. (1999). Three dimensions of vocabulary development. Studies in Second Language Acquisition, 21, 303-317.

Kelly, P. (1985). A dual approach to FL vocabulary learning: the conjoining of listening comprehension and mnemonic practices. Catholic University of Louvain, Belgium: Unpublished doctoral thesis.

Li, M., \& Kirby, J.R. (2015). The effects of vocabulary breadth and depth on English reading. Applied Linguistics, 36(5), 611-634.

Mason, J. (2002). Qualitative researching. London: Sage.

McLean, S., \& Kramer, B. (2015). The creation of a New Vocabulary Levels Test. Shiken, 19 (2), 1-11.

Meara, P. (1996). The vocabulary knowledge framework. Retrieved November 2, 2019, from vocabulary acquisition research group virtual library: http://www.swansea. ac.uk/cals/calsres/vlibrary/pm96d.htm.

Mehrpour, S., Razmjoo, S.A., \& Kian, P. (2011). The relationship between depth and breadth of vocabulary knowledge and reading comprehension among Iranian EFL learners. Journal of English language teaching and learning, 2(222), 97-127.

Nation, I. S. (2001). Learning vocabulary in another language. Cambridge: Cambridge University Press.

Nation, I. S. (1990). Teaching and learning vocabulary. New York: Newbury House.

Onwuegbuzie, A. J., \& Collins, K. M. (2007). A typology of mixed methods sampling designs in social science research. The Qualitative Report, 12 (2), 281-316.

Poate, C. D., \& Daplyn, P. F. (1993). Data for Agrarian Development. Cambridge: Cambridge University Press.

Ratner, B. (2009). The correlation coefficient: Its values range $+1 /-1$, or do they? Journal of targeting, measurement and analysis of marketing, 17, 139-142. 
Read, J. (1993). The development of a new measure of SL vocabulary knowledge. language testing, 10, 355-371.

Read, J. (1998). Validating a test to measure the depth of vocabulary knowledge. In A. Kunnan, Validation in Language assessment (pp. 41-60). Mahwah, N.J: Lawrence Erlbaum.

Saunders, M. (2012). Research Methods for Business Students. Harlow: Pearson.

Schmitt, N. (2005). Current trends in vocabulary learning and teaching. In J. Cummins, \& C. Davison, Handbook of English language teaching. Dordrecht, Boston: Kluwer Academic Publishers.

Shen, Z. (2008). The roles of depth and breadth of vocabulary knowledge in EFL reading performance. Asian Social Science, 4 (12), 135-137.

Tashakkori, A., \& Teddlie, C. (2003). Handbook of mixed methods in social and behavioural research. Thousand Oaks: Sage Publications.

URT. (2016). Basic demographic and socio-economic profile, Dodoma Region. Dar es Salaam: National Bureau of Statistics (NBS).

Vermeer, A. (2001). Breadth and depth of vocabulary in relation to L1/SL acquisition and frequency of the input. Applied Psycholinguistics, 2, 217-234.

Zhang, X., \& Lu, X. (2015). The relationship between vocabulary learning strategies and breadth and depth of vocabulary knowledge. The modern language journal, 99(4), 740-753. 